\title{
Pengembangan Antena Fleksibel Mikrostrip Bowtie
}

\section{Development of Flexible Microstrip Bowtie Antenna}

\author{
Levy Olivia Nur ${ }^{1 *}$, Muhammad Fathan Hizbuddin², Bambang Setia Nugroho ${ }^{3}$ \\ ${ }^{123}$ School of Electrical Engineering, Telkom University, \\ J1 Telekomunikasi, Dayeuh Kolot, Bandung, Indonesia \\ levyolivia@telkomuniversity.ac.id ${ }^{1}$, hizbuddingfathan@gmail.com², \\ bambangsetianugroho@telkomuniversity.ac.id ${ }^{3}$
}

\begin{abstract}
Abstrak - Antena mikrostrip fleksibel dengan patch bowtie dipresentasikan dalam penelitian ini. Antena berbahan fleksibel Duroid Roger $3003 \mathrm{C}$ dengan frekuensi 2,45 GHz telah dirancang dan diukur. Penelitian ini mengusulkan penggunaan antena dengan bahan fleksibel untuk komunikasi saat dan pasca terjadi bencana alam seperti gempa atau erupsi gunung berapi. Pada makalah ini dilakukan modifikasi dengan penambahan elemen parasitic untuk meningkatkan bandwidth dan mengefektifkan pola radiasi. Pola radiasi, gain, S-parameter, dan VSWR dievaluasi dalam kondisi normal, bend, dan on-body dengan simulasi nilai SAR. Hasil pengukuran terhadap parameter-parameter tersebut menunjukkan bahwa antena fleksibel patch bowtie ini dapat digunakan dalam kondisi on-body centric.
\end{abstract}

Kata kunci: antenna microstrip, fleksibel, elemen parasitic, nilai SAR

\begin{abstract}
This paper reports the development of flexible microstrip antenna. The antenna is developed using roger 3003C flexible with the frequence $2.45 \mathrm{GHz}$, which is designed and characterized its performance. The resulted antenna can be used for rescue and search communication during and after the natural disaster including earthquake and volcano eruption. In this report, the modification of antenna by adding the parasitic element is investiagted to improve the bandwitth and make more effective the radiation pattern. The radiation pattern, gain, s-parameter, and VSWR are studied in several condition including normal, bend, and on-body using SAR value simulation. The measurement results of these parameters indicate that the flexible microstrip bowtie antenna can be used in on-body centric conditions.
\end{abstract}

Keywords: microstrip antenna, flexible, parasitic element, SAR value

\section{Pendahuluan}

Kondisi pencarian dan penyelamatan pada berbagai bencana alam yang banyak terjadi di Indonesia sering membutuhkan kecepatan dan monitoring yang terus menerus agar kebutuhan untuk tindakan penyelamatan dapat dijalankan. Kegiatan pertolongan dan evakuasi yang cepat tersebut sangatlah penting untuk menyelamatkan jiwa manusia yang terdampak bencana. Kegiatan ini biasa dilakukan oleh tim SAR atau search and rescue. Pada proses pencarian dan evakuasi, tim SAR menggunakan Teknik Track spacing dengan jalur pencarian tidak berdekatan, sehingga sangat dibutuhkan komunikasi yang baik antar tim untuk saling berkoordinasi satu

TELKA, Vol.5, No.2, November 2019, pp. 130 138

ISSN (e): 2540-9123

ISSN (p): 2502-1982 
dengan yang lainnya. Salah satu perangkat penting pada sistem monitoring secara real time adalah antena. Secara khusus jenis antenna fleksibel sangat dibutuhkan agar dapat dilekatkan pada pakaian atau tubuh manusia saat proses penyelamatan berlangsung [1].

Pada dekade terakhir ini penelitian mengenai antena fleksibel telah berkembang dengan pesat. Antena fleksibel banyak digunakan untuk aplikasi militer, olah raga, kesehatan, dan radar. Antena fleksibel merupakan jenis antena yang menggunakan bahan fleksibel sebagai substrat. Penggunaan bahan fleksibel pada antena membuat antena lebih ringkas, ringan dan tipis sehingga lebih nyaman digunakan terutama pada saat penyelamatan dan pencarian yang membutuhkan fleksibilitas tinggi. Felksibiltas yang tinggi juga dibutuhkan untuk mengidentifikasi secara langsung (real time) berbagai pengukuran dan monitoring untuk aplikasi pada olahraga maupun kesehatan. Antena fleksible ini akan dapat diaplikasikan pada berbagai bagian tubuh manusia [24]. Bagian tubuh manusia memiliki bentuk dan ukuran yang berbeda sehingga perlu dilakukan proses pengujian bending untuk mengetahui apakah antena dapat bekerja dengan baik pada kelengkungan tertentu, serta dilakukan uji on-body untuk mengevaluasi antena pada saat pengaplikasian pada tubuh. Penelitian ini berkonsentrasi pada merancang antena berbahan fleksibel untuk kebutuhan wearable communication. Pada makalah ini dilaporkan mengenai pengembangan antenna fleksibel dengan menggunakan bentuk patch bowtie dengan bahan substrat Roger 3003C dan tembaga sebagai konduktor. Parameter antena yang diukur antara lain nilai gain, pola radiasi, VSWR, return loss, polarisasi. Pengujian antena dilakukan dalam tiga kondisi yaitu kondisi normal, saat dibengkokan dan on-body. Pengujian fleksibilitas antena dengan membengkokkan antena untuk membuktikan bahwa antena fleksibel mempunyai sifat yang dinamis dan mudah di aplikasikan pada perangkat wearable. Pengujian on-body dilakukan dengan meletakan antena pada beberapa bagian tubuh manusia dengan hasil akhir nilai gain, pola radiasi dan Spesific Absorption Ratio yang sesuai persyaratan dan bisa diaplikasikan untuk aplikasi pencarian dan penyelamatan di frekuensi Industrial, Scientific and Medical (ISM) 2,45 GHz.

\section{Desain Penelitian}

Antena yang dirancang merupakan antena mikrostrip dengan patch berbentuk bowtie dengan menambahkan elemen parasitik disamping catuan. Antena bekerja pada frekuensi ISM Band 2.45 $\mathrm{GHz}$ dengan bahan yang digunakan pada penelitian ini sebagai substrat adalah duroid roger 3003C dengan permitivitas $\varepsilon_{r}=3$ dan ketebalan $h=0.75 \mathrm{~mm}$. Antena Patch bowtie merupakan pengembangan dari antena bowtie yang masuk dalam jenis antena dipole [5]. Kelebihan bentuk bowtie yaitu mempunyai radiator besar dan menghasilkan frekuensi kerja yang sama pada kedua sisinya. Dimensi dari patch bowtie didapatkan dari persamaan (1) [6]

$$
\lambda_{g}=\frac{c}{f x \sqrt{\varepsilon_{r}}}, a=\frac{1}{2} \lambda_{g},
$$

dengan $\varepsilon_{r}=3, c=3 \times 10^{8}$, dan $f_{r}=2.45 \times 10^{9}$. Dari hasil perhitungan diatas didapatkan dimensi antena yang ditunjukan pada Tabel.1 dan layout desain antena ditunjukan pada Gambar 1.

Tabel 1. Dimensi Antena Patch Bowtie

\begin{tabular}{|l|l|l|l|l|l|l|l|l|l|}
\hline Dimensi & a & Wf & Lf & gap & L & W & gap' & Wc & Lc \\
\hline Nilai $(\mathrm{mm})$ & 30,3 & 3 & 24 & 0.5 & 45 & 70 & 4.2 & 20 & 4 \\
\hline
\end{tabular}

ISSN (e): 2540-9123

ISSN (p): 2502-1982 


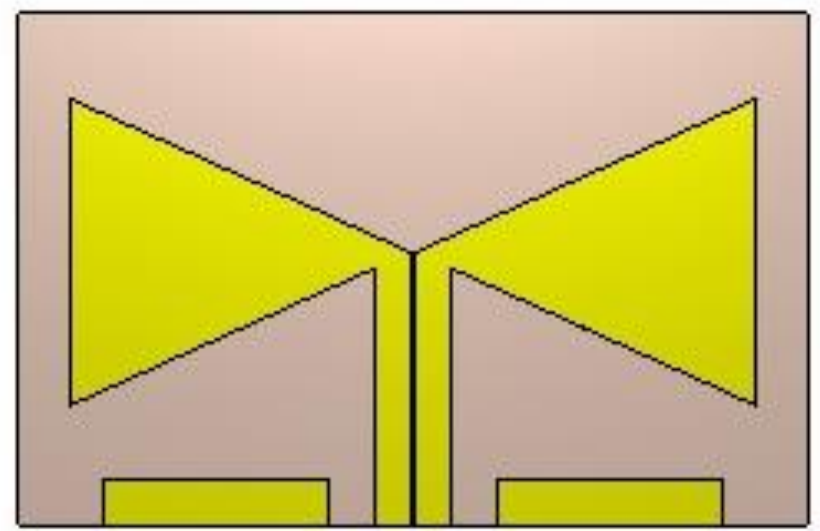

Gambar 1. Flexible microstrip patch bowtie.

\section{Hasil dan Pembahasan}

\subsection{Performansi Antena Fleksibel}

Dari pengembangan antenna yang telah dilakukan maka dapat ditentukan perhitungan dengan proses simulasi, yang selanjutnya dapat dilakukan fabrikasi untuk menghasilkan purwarupa. Purwarupa hasil pabrikasi antena dapat dilihat pada Gambar 2. SMA connector digunakan sebagai konektor untuk catuan. Pengukuran antena hasil fabrikasi dilakukan untuk memvalidasi hasil simulasi yang telah dilakukan. Pengukuran return loss dilakukan untuk melihat daerah kerja antena, hasil simulasi dapat dilihat pada Gambar 3 menunjukan bahwa nilai return loss yang dicapai pada frekuensi $2.45 \mathrm{GHz}$ sebesar $-28.48 \mathrm{~dB}$ dengan rentang frekuensi kerja 2.2 GHz sampai $2.68 \mathrm{GHz}$. Pengukuran return loss antena pabrikasi pada Gambar 4 menunjukan nilai return loss pada frekuensi $2.45 \mathrm{GHz}$ sebesar $-21,68 \mathrm{GHz}$ dengan rentang frekuensi kerja 2.34 $\mathrm{GHz}$ sampai $2.6 \mathrm{GHz}$. Pergeseran terjadi dari hasil simulasi dengan hasil pengukuran disebabkan faktor pabrikasi, meskipun demikian hasil antara simulasi dan pengukuran pada frekuensi resonansi $2.45 \mathrm{GHz}$ menunjukan nilai yang baik.

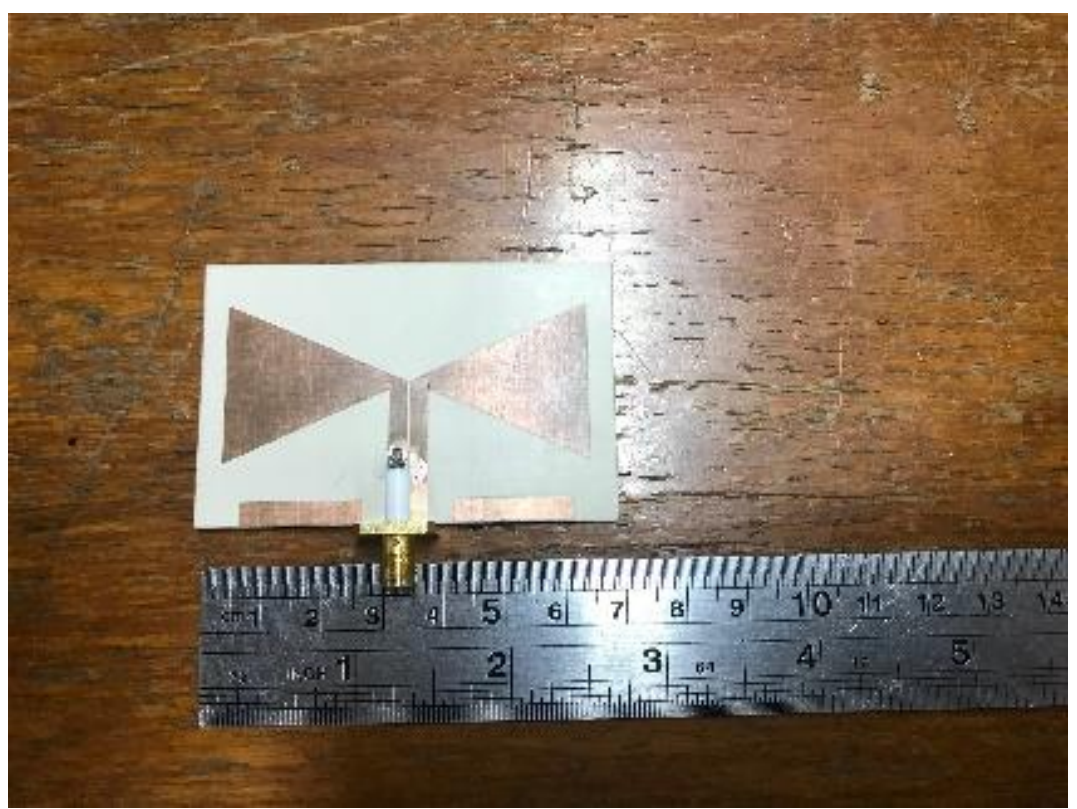

Gambar 2. Prototipe antenna felksibel. 


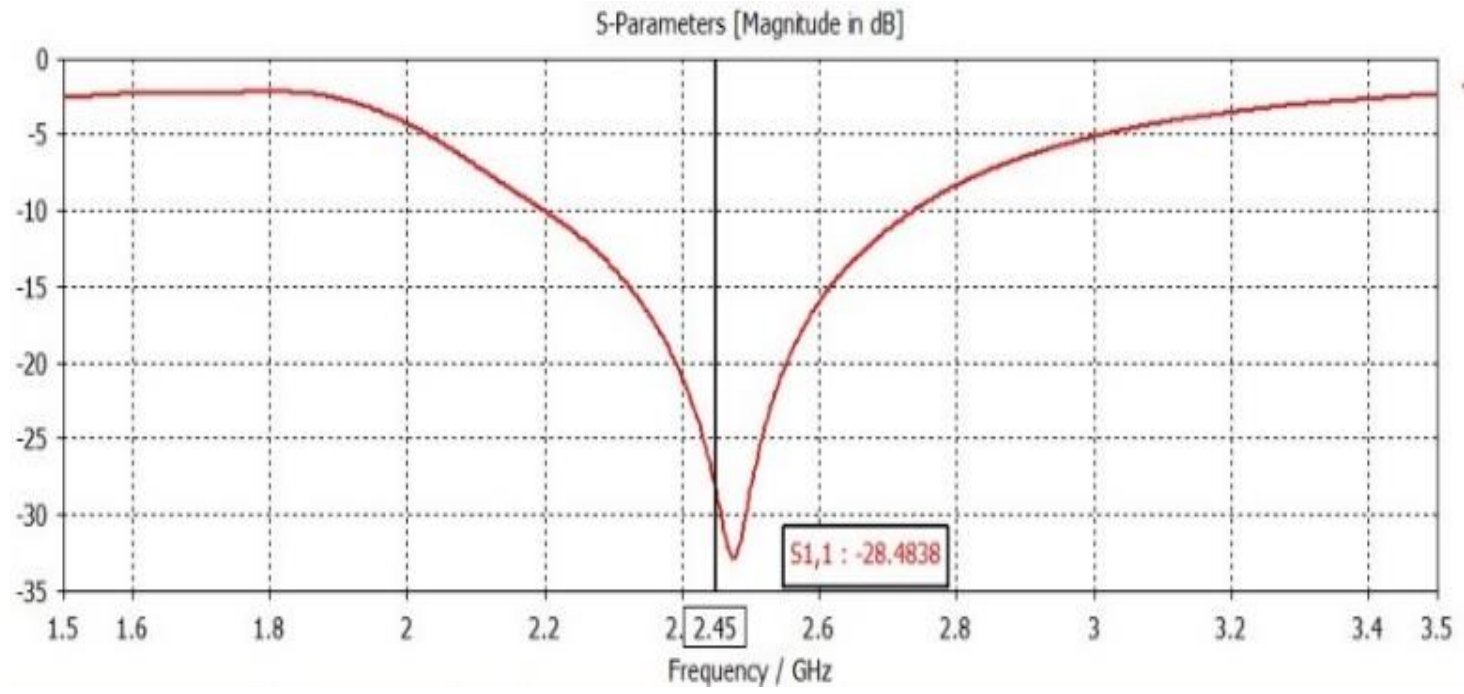

Gambar 3. Grafik nilai return loss hasil simulasi antena fleksibel.

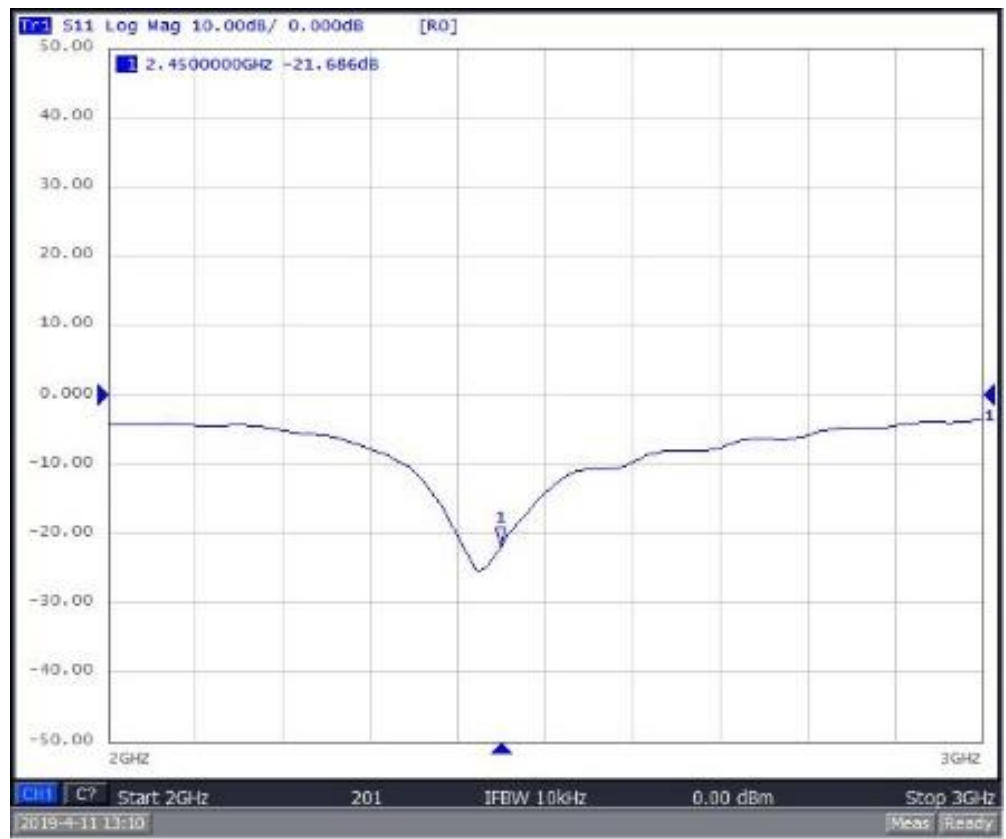

Gambar 4. Grafik nilai return loss hasil pengujian antena fleksibel.

Pengukuran VSWR dilakukan menggunakan Network Analyzer dan hasil pengukuran dapat diliihat pada Gambar 5. Hasil VSWR pada frekuensi resonansi $2.45 \mathrm{GHz}$ terlihat baik dengan nilai $1.4 \mathrm{~dB}$ dengan bandwidth sebesar $350 \mathrm{MHz}$. Hasil pengukuran mengalami pergeseran nilai VSWR bila dibandingkan dengan hasil simulasi dengan nilai $1.07 \mathrm{~dB}$ seperti telihat pada Gambar 6. Pergeseran nilai VSWR tersebut berdampak pada penurunan bandwith dengan nilai awal hasil simulasi sebesar $530 \mathrm{MHz}$. Pergeseran nilai tersebut disebabkan faktor konektor pada antena purwarupa yang tidak identik dengan simulasi. Sementara itu, pola radiasi dalam E dan H-plane terlihat pada Gambar 7. 


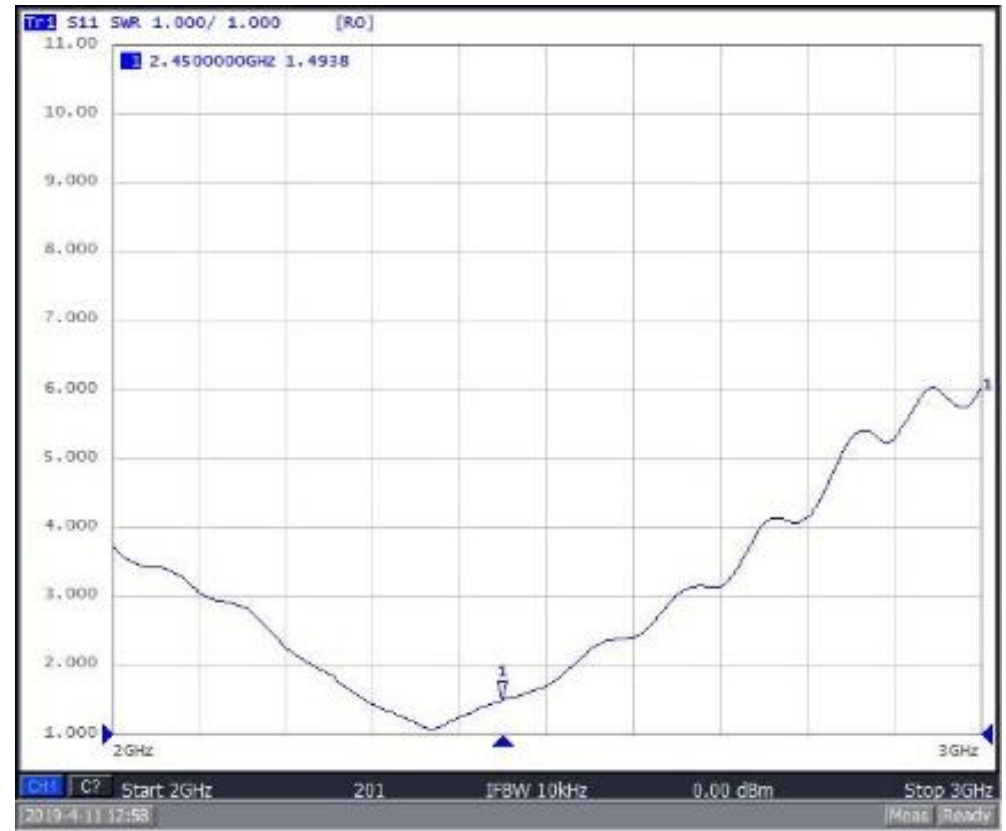

Gambar 5. Nilai VSWR hasil pengukuran.

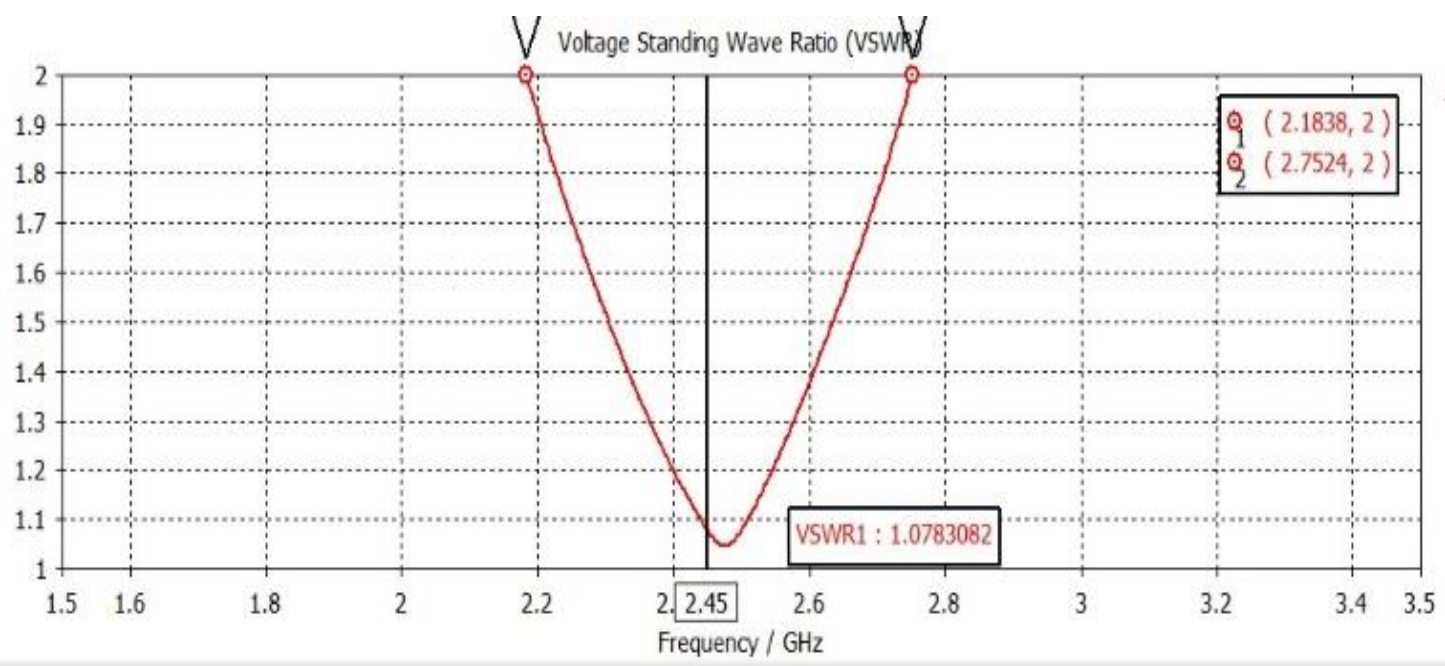

Gambar 6. Simulasi VSWR dari antena

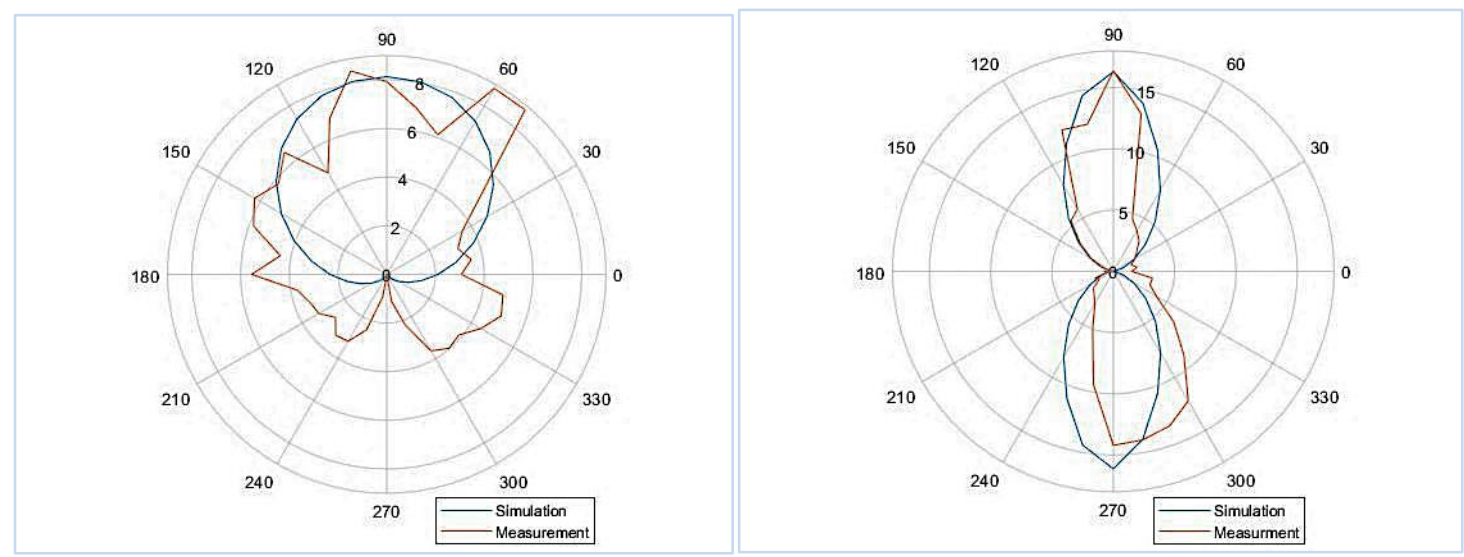

Gambar 7. Perbandingan pola radiasi hasil simulasi dan pengukuran antena fleksibel. 
Pengukuran pola radiasi dalam $\mathrm{E}$ dan $\mathrm{H}$ plane terlihat baik dibandingkan dengan simulasi. Pola radiasi antena pada simulasi dan hasil pengukuran menunjukan hasil pola radiasi uni directional. Hasil pengukuran gain pada pengukuran antena mendapatkan nilai sebesar 2,38 dBi dan untuk simulasi sebesar 3,2 dBi. Perbedaan antara hasil pengukuran dan simulasi disebabkan oleh ketidak identikan antara antena simulasi dan pengukuran akibat proses fabrikasi terutama pada proses pencatuan.

\subsection{Bending dan Pengukuran Body Centric}

Pada bagian ini menjelaskan dampak fleksibel antena pada saat kondisi kelengkungan dan diaplikasikan pada tubuh. Faktor yang diuji kelengkungan adalah antena dilengkungkan dengan tabung diameter $7 \mathrm{~cm}, 9 \mathrm{~cm}$ dan $14 \mathrm{~cm}$. Pada pengujian body centric dilakukan uji pada bagian kepala sebagai phantom dengan mengevaluasi nilai SAR. Faktor kelengkungan sangat berpengaruh pada antena yang akan diimplentasikan pada tubuh manusia. Perancangan antena ditujukan mengikuti bentuk tubuh untuk memudahan penggunaan. Untuk mendemonstrasikan kondisi bending pada tubuh, tabung silinder digunakan untuk pengujian kelengkungan. Pada pengujian kelengkungan ini digunakan 3 tabung silinder dengan ukuran berbeda yaitu $7 \mathrm{~cm}, 9$ $\mathrm{cm}, 14 \mathrm{~cm}$, masing-masing ukuran merepresantikan diameter lengan, dada, dan kepala sebagaiana ditunjukkan pada Gambar 8.

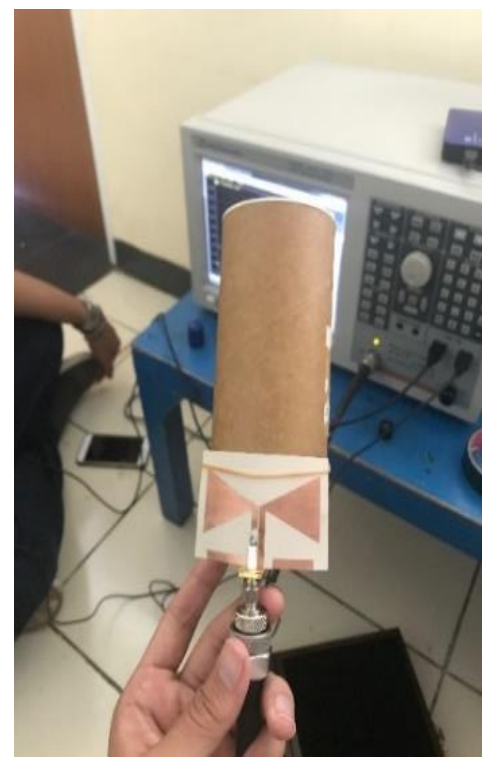

(a)

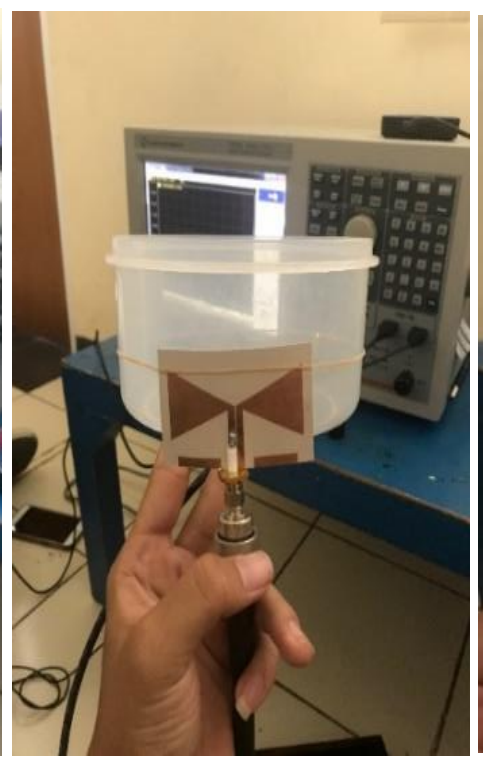

(b)

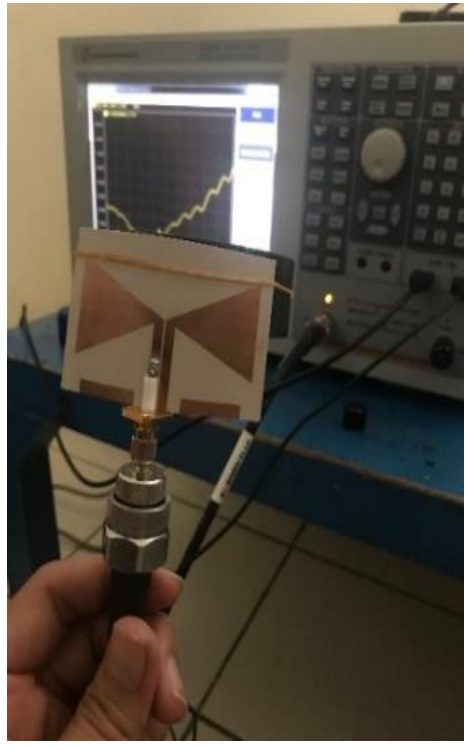

(c)

Gambar 8. Bending measurment setup (a) Bending $7 \mathrm{~cm}$ (b) Bending $14 \mathrm{~cm}$ (c) Bending $9 \mathrm{~cm}$

Pola radiasi dalam kondisi lengkung dapat dilihat pada Gambar 9. Pola radiasi terlihat baik pada kondisi melengkung dalam beberapa ukuran. Kelengkungan berpengaruh pada beamwidth, semakin antena melengkung, beamwidth semakin besar. Gain hasil pengukuran pada kondisi kelengkungan $7 \mathrm{~cm}, 9 \mathrm{~cm}$, dan $14 \mathrm{~cm}$ secara berurutan adalah 1,2 dBi, 1,6 dBi, dan 2,08 dBi mengalami penurunan jika dibandingkan dalam kondisi normal. 


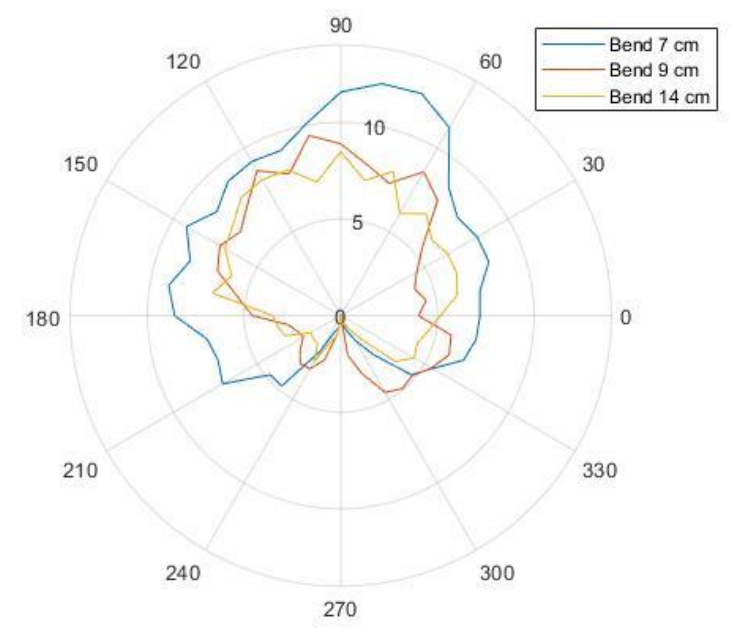

Gambar 9. Pengukuran Pola Radiasi pada kondisi Bending

Pengukuran body centric dilakukan dengan menggunakan kepala sebagai phantom. Pada pengukuran ini dilakukan uji terhadap pola radiasi, return loss, dan spesicific absorption rate. Pengukuran body centric dilakukan untuk mendapatkan parameter yang sesungguhnya karena pada pengaplikasiannya antena fleksibel ini diletakan pada tubuh manusia. Proses pengukuran dapat dilihat pada Gambar 10.

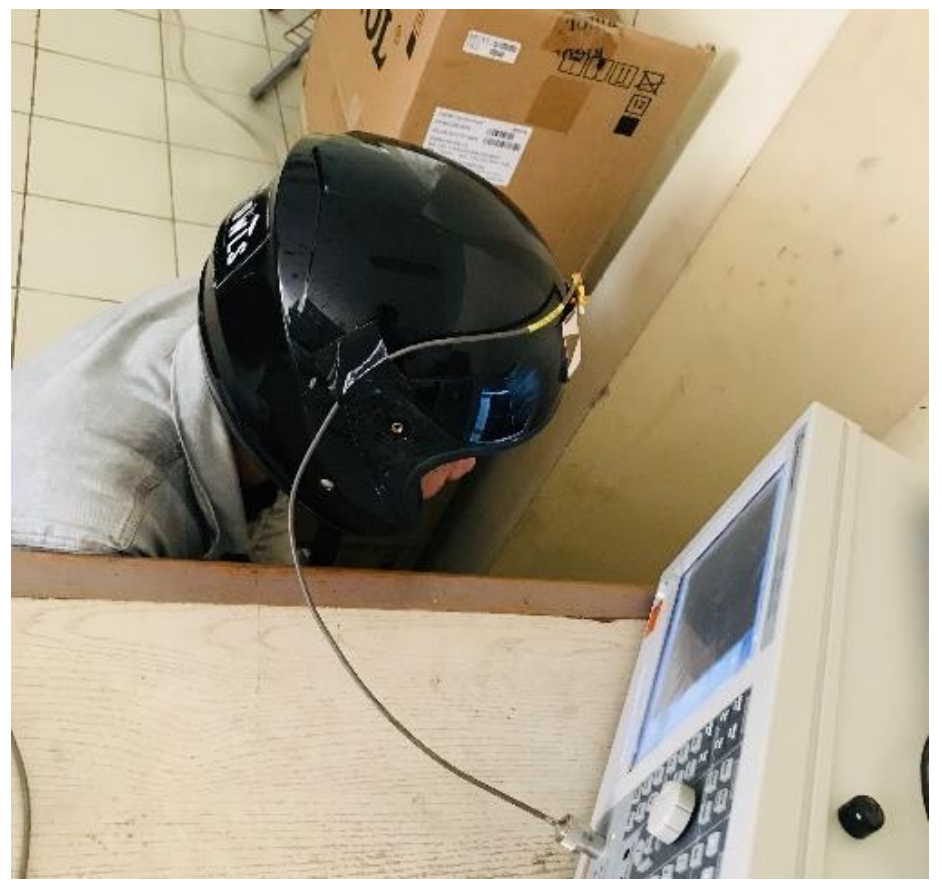

Gambar 10. Proses Pengukuran Antena pada kondisi on-body.

Pola radiasi hasil pengukuran dapat dilihat pada Gambar 11. Pola radiasi mengalami perubahan arah dibandingkan dengan hasil dalam kondisi normal. Hal ini diakibatkan oleh helm dan kepala manusia sebagai reflektor antena. Pengukuran gain antena juga dilakukan pada penelitian ini, gain mengalami kenaikan dibandingkan dengan antena kondisi normal hasil pengukuran gain bernilai 4,4 dBi sedangkan kondisi normal hanya 2,38 dBi. 


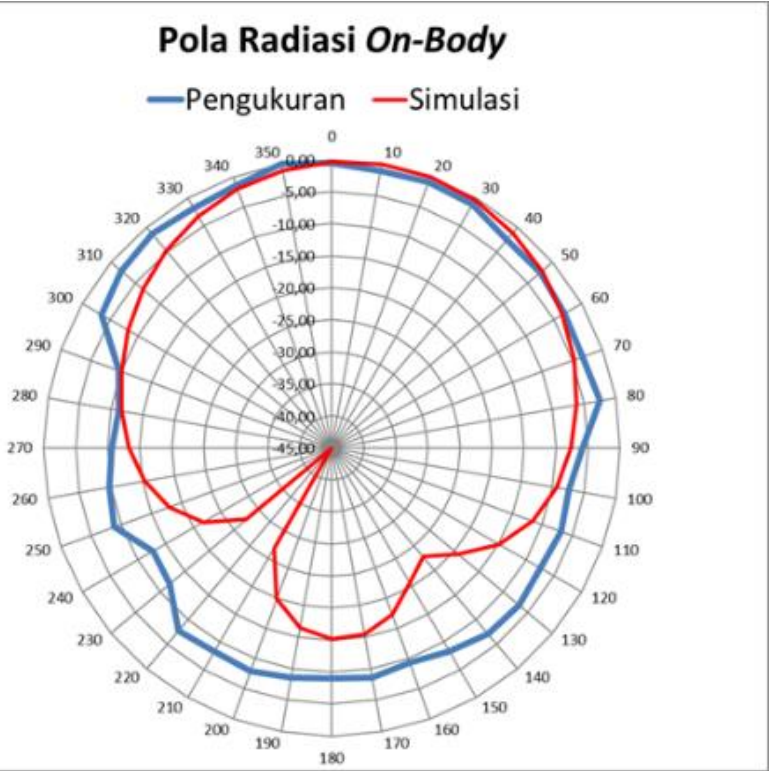

Gambar 11. Pola Radiasi Hasil Pengukuran Antena pada kondisi on-body.

Fleksible antenna akan diaplikasikan untuk penggunaan pada tubuh. Penggunaan antena pada tubuh sangat mempengaruhi kondisi tubuh manusia, gelombang elektromagnetik yang diserap tubuh secara berlebih akan menggangu kesehatan sehingga perlu dilakukan simulasi specific absorption rate (SAR). Berdasarkan standar internasional yang ditentukan oleh Federal Communication committee (FCC), batas untuk paparan dari perangkat radio yang dapat ditoleransi tubuh adalah tingkat SAR dari 1,6 Watt per kilogram $(1,6 \mathrm{~W} / \mathrm{kg})$. Hasil simulasi SAR pada antena fleksibel ini adalah 0,2 W/kg, dapat dilihat pada Gambar 12.

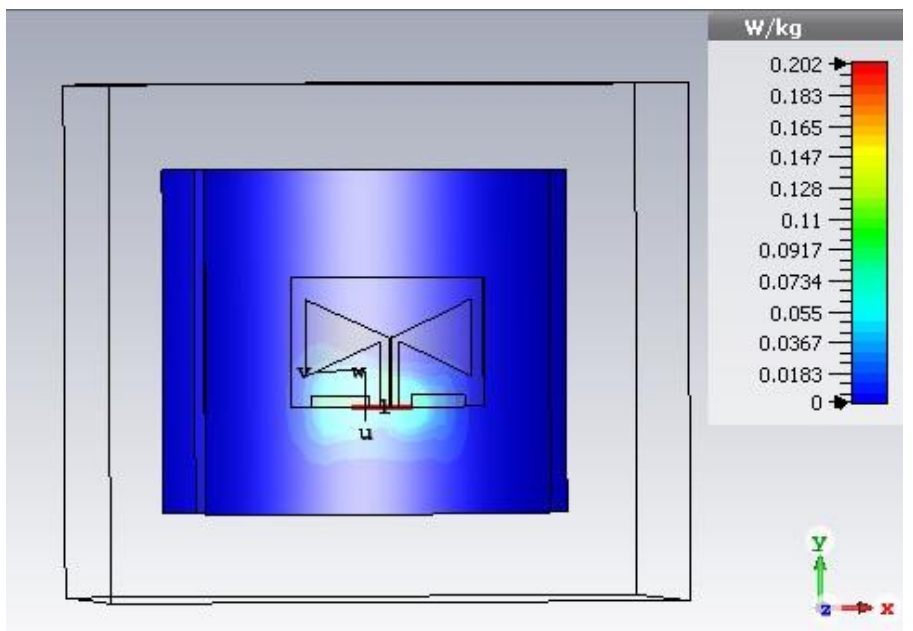

Gambar 12. Specific absorption rate dari antena.

\section{Kesimpulan}

Makalah ini mengevaluasi dan membangun fleksibel antena patch bowtie dengan menambahkan elemen parasitik. Antena fleksibel menguji beberapa parameter dalam kondisi normal, lengkung, dan body centric. Antena dapat bekerja dengan baik pada kondisi normal sedangkan pada kondisi bending mengalami penurunan gain. Pola radiasi pada kondisi lengkung tidak berdampak secara signifikan. Performansi VSWR dan return loss dalam kondisi lengkung tidak mengalami perubahan yang signifikan sehingga masih dapat bekerja dengan baik pada 
kondisi lengkung. Pengukuran on-body centric dilakukan dengan menguji pola radiasi, gain, dan SAR. Pola radiasi pada body centric mengalami perubahan arah yang cukup signifikan dan gain pada antena body centric mengalami kenaikan. SAR yang disimulasikan pada antena fleksibel pada pengaplikasian di kepala memenuhi standar dibawah ambang batas toleransi SAR sehingga antena fleksibel patch bowtie ini dapat digunakan dalam kondisi on-body centric.

\section{Ucapan Terima kasih}

Penelitian ini sebagian didukung oleh Penelitian Dasar Unggulan Perguruan Tinggi dari Kementerian Riset, Teknologi, dan Pendidikan Tinggi, Republik Indonesia, di bawah Kontrak No. 2879/L4/PP/2019.

\section{Referensi}

[1] R. Joshi, C. Constantinides, S. K. Podilchak, and P. J. Soh, "Dual-Band Folded-Shorted Patch Antenna for Military Search and Rescue Operations and Emergency Communications," 2018 18th Int. Symp. Antenna Technol. Appl. Electromagn., pp. 1-2, 2018.

[2] C. Parmar and S. Joshi, "Wearable textile patch antenna for on-body communications," Glob. Conf. Commun. Technol. GCCT 2015, no. Gcct, pp. 921-924, 2015.

[3] R. Salvado, C. Loss, Gon, and P. Pinho, "Textile materials for the design of wearable antennas: A survey," Sensors (Switzerland), vol. 12, no. 11, pp. 15841-15857, 2012.

[4] N.T Susyanto, T Yunita, L O Nur, "Antena Mikrostip Bahan Tekstil Frekuensi 2.45 GHz untuk Aplikasi Telemedis." Semnastek, 2018

[5] E. Sunny, RP Astuti, BS Nugroho, "Perancangan dan Analisis Antena Mikrostrip MIMO Modified Shape Bow-tie pada Frekuensi 28GHz', eProceedings of Engineering Telkom University, 2018

[6] C. A. Balanis, Antenna Theory. Fourth Edition, 2016. 